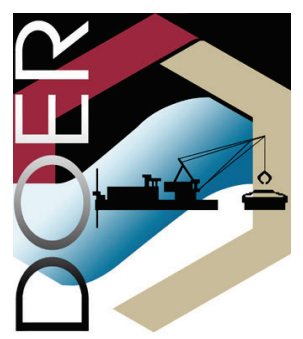

ERDC TN-DOER-E42

March 2017

\title{
Using the Fish Larvae and Egg Exposure System (FLEES) to Generate Effects Data for Informing Environmental Windows
}

by Justin L. Wilkens and Burton C. Suedel

PURPOSE: The Fish Larvae and Egg Exposure System (FLEES) was designed to simulate the resuspension of sediment related to dredging operations and has been used over time to generate biological response data for dredging projects where environmental windows (EW) severely restrict dredging operations (Lutz et al. 2012). This technical note focuses on the physical and behavioral effects of resuspended sediment for the purpose of developing better informed EWs for dredging operations.

INTRODUCTION: During a dredging operation a portion of the disturbed sediment is resuspended into the water column creating a plume. In addition to being resuspended, the sediment may be transported away from the dredge by ambient conditions before settling out of the water column. The combination of these two mechanisms means that an aquatic organism found near a dredge operation may be exposed to resuspended sediments and possibly suffer adverse effects. Therefore, EWs are routinely used as a management practice to reduce or eliminate the risk of potentially harmful impacts of resuspended sediments from dredging activities on aquatic resources (Suedel et al. 2008).

Environmental windows are most commonly established to protect endangered, threatened or commercially valuable species, such as the walleye (Sander vitreus) and smallmouth bass (Micropterus dolomieu) (Reine et al. 1998). The supporting justification for imposing EWs often focuses on how dredge activities may potentially physically disturb a fish's ability to complete a specific part of its life cycle due to resuspended sediment. However, there is limited information concerning species-specific biological effects relevant to such resuspended sediment (Wilber and Clarke 2001) which proposes the question of the accuracy and effectiveness of using EWs as a risk management tool.

For these reasons, the FLEES was designed to simulate the resuspension of sediment similar to that caused by dredge operations, and to determine its effects on the early life stages of aquatic organisms. Studies using FLEES use fine-grained sediment particles which are most likely to remain in suspension and migrate away from an active dredge. The FLEES is capable of testing fish eggs and larvae, but it is also retrofitted to accommodate other aquatic organisms. The resulting biological response data can then be used to inform the revision of existing EWs. The FLEES has been used for several years across multiple dredging projects to generate effects data for various aquatic species. These results are presented below to provide an overall assessment of effects data generated to date. 
FISH LARVAE AND EGG EXPOSURE SYSTEM (FLEES): The FLEES is a flow through exposure system containing 15 temperature-controlled $20 \mathrm{~L}$ aquaria. To begin studies, sediments are sieved to yield fine-grained (fine sands, silts, and clays) particles and then introduced into a slurry tank. A data acquisition device and LabVIEW software (National Instruments, Austin, Texas) is used to integrate turbidity sensors (OBS-3, 0-1,000 Nephelometric Turbidity Unit [NTU], Campbell Scientific Inc., Logan, Utah) with solenoid valves to build a computer application that both continuously monitors and records turbidity in each aquarium while introducing sediment from the slurry tank to maintain specific NTUs (e.g., 100 NTU). A magnetic drive pump positioned separately as part of each aquarium is used to recirculate water to maintain the sediment in suspension. Small exposure chambers designed to hold fish eggs and larvae are suspended inside the aquaria. Larger fish or sessile organisms, such as shellfish, are stocked into the aquarium and a screen is placed on the bottom of the aquarium to prevent the organism from contacting the pump.

An NTU-TSS (Total Suspended Solids in $\mathrm{mg} / \mathrm{L}$ ) relationship is established by gravimetric analysis at least once daily during a study. The concurrent measurements are then used to accurately predict TSS for the remainder of the day based on NTU measurements recorded at specified intervals by the computer. The TSS measurements are used to develop exposure concentrations because they quantify the mass of particles present in the water column and directly relate to physical and behavioral effects such as abrasion, loss of orientation and reduced feeding exhibited by some organisms (Wilber and Clarke 2001).

To date, the FLEES has tested sediments collected from areas routinely dredged to maintain navigation channel depth, in close proximity to species of concern, that are known to lack historical contamination. The sediments are analyzed for chemical contamination and characterized for grain size distribution as part of the maintenance dredging program. The sediments typically have low to non-detectable levels of contamination so that the physical effect of suspended sediment is the only stressor being evaluated. Other physical and chemical characteristics are conducted on a case-by-case basis to meet study requirements.

FLEES CASE STUDIES: To describe potential adverse effects of resuspended sediments, experiments have been performed on species of concern, including walleye (S. vitreus) and smallmouth bass (M. dolomieu) eggs and fry; adult eastern oyster (Crassostrea virginica) and Atlantic sturgeon (Acipenser oxyrinchus oxyrinchus) fingerlings. Concerns for these receptors focused on dredge plumes that spread by dredge activities or that were carried by ambient conditions (e.g., currents, tides) away from the dredge to areas where the critical life stages of the species of concern may be exposed. Target endpoints were project specific, including survival, growth, condition, gross morphology and behavior.

Site-specific information about the dredging project and the area of potential exposure were considered when selecting an exposure concentration and duration. Factors considered included dredge method (e.g., type, speed, and duration), ambient conditions, and relative proximity of the organism to the dredge operation. Other factors may be considered on a case-by-case basis as required for the study. For the FLEES studies (walleye, smallmouth bass, eastern oyster, and Atlantic sturgeon), the effects of resuspended sediments were evaluated at $0,100,250$, and 500 $\mathrm{mg} / \mathrm{L}$ TSS because these targeted concentrations conservatively reflected the range of 
concentrations measured in the field near the dredge projects and the area of potential exposure (Reine et al. 2007; Wilber and Clarke 2001).

Exposure duration associated with a dredge plume is influenced by dredge method as well as site-specific conditions such as sediment type (Wilber and Clarke 2001). For FLEES studies, test organisms were subjected to continuous exposures of TSS and all studies were terminated after 72 hours, with the exception of the oyster study, which was terminated after 7 days. These durations were selected because the dredge plumes from the study operations were unlikely to last longer than this duration at any given point along the channel being dredged. The following sections describe studies conducted to evaluate the effects of suspended sediments on walleye, smallmouth bass, eastern oyster, and Atlantic sturgeon, emphasizing the collective results and what they mean in a broader context for managing the effects of suspended sediments.

WALLEYE IN LAKE ERIE: In the Great Lakes of North America, walleye can spawn in proximity to areas that are periodically maintained by dredging, which has been the supporting rationale for the setting of an EW in Maumee Bay, located in western Lake Erie (Reine et al. 2007). In western Lake Erie, walleye spawning may begin as early as late March, peak in April and extend in to May (Roseman et al. 1996). To describe the effects of resuspended sediment on the eggs and swim-up fry of walleye, several experiments were performed using site-specific sediment and different sources of fish during 72 hour exposures. Eggs were stocked into exposure chambers and placed in each FLEES aquarium for exposure. Northern and southern strain walleye eggs and fry obtained from state fish hatcheries located in Ohio and Mississippi, respectively, were used in the experiments and were exposed to sediment collected from the navigation channel in Maumee Bay.

Northern and southern strain egg hatching rates were within reported ranges for this species (Suedel et al. 2012, 2014). Data indicated no statistically significant $(\mathrm{P}<0.05)$ effects of suspended sediment on hatching success (Figure 1). Gross morphological observations of exposed fry yielded no evidence of detrimental effects. The mean number of viable eggs was slightly reduced after exposure to $500 \mathrm{mg} / \mathrm{L}$ when compared to that of controls. Likewise, mean percent hatch was reduced slightly in the $500 \mathrm{mg} / \mathrm{L}$ compared with that of controls. These data suggested a possible deterioration in both endpoints at the $500 \mathrm{mg} / \mathrm{L}$ concentration, although this reduction was not found to be statistically significant. These experimental results indicate that walleye eggs are relatively tolerant to exposures likely to be encountered at dredging projects as performed in the Great Lakes region.

SMALLMOUTH BASS IN THE GREAT LAKES: In the Great Lakes of North America, smallmouth bass (SMB) can spawn in proximity to areas that are periodically maintained by dredging; an activity that has been used to justify the setting of an EW to protect spawning populations, typically from mid-May to mid-July. Spawning occurs in the littoral zone where the males construct a nest usually over hard substrate. The SMB courting and mating then ensues. After mating, the male provides parental care by fanning away settling sediments and protecting the nest form predators. Parental care continues through hatch out and generally ends once larval fish become independent (Cooke et al. 2006). For the FLEES study, SMB eggs (24-48 hours old) and swim-up fry (11-13 days old) obtained from state hatcheries in Illinois and Texas were 
exposed in aquaria for 72 hours to sediment collected from two harbors; one on Lake Michigan and one on Lake Erie (Suedel et al. 2016 In prep) ${ }^{1}$.

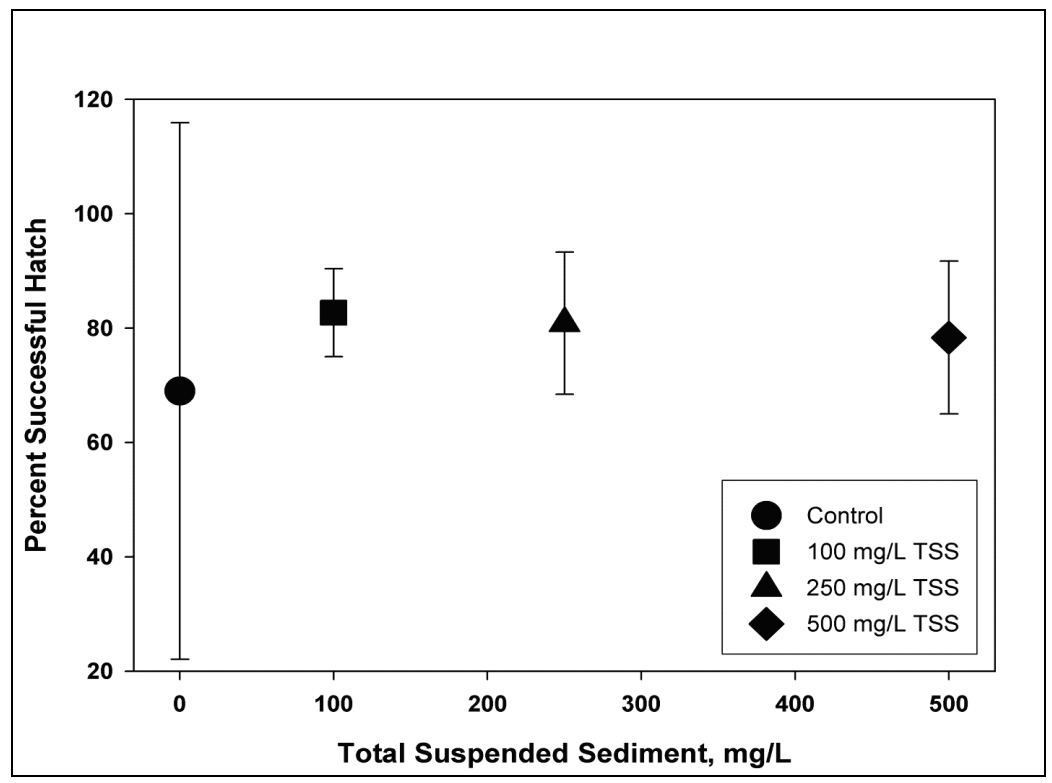

Figure 1. Percent of successful hatch of northern strain walleye eggs following control and target TSS treatment exposures (Suedel et al. 2014).

For the egg experiment, hatching was completed by the end of exposure period and egg mortality was less than 5\% (Table 1). However, eggs exposed to TSS concentrations greater than $100 \mathrm{mg} / \mathrm{L}$ resulted in reduced survival of post-hatch larval fish. The combination of low egg mortality and presence of egg shells indicated mortality of larval fish occurred after hatching. In the experiment with swim-up fry, survival was greater than $90 \%$ at the highest exposure concentration $(500 \mathrm{mg} / \mathrm{L})$, but growth (\% change in weight) was significantly reduced $(\mathrm{P}<0.05)$ when the exposure concentration exceeded $100 \mathrm{mg} / \mathrm{L}$ (Table 1). Samples of swim-up fry were held for a 7 and 26 day post-exposure grow-out period. Growth (specific growth rate: $2.35-6.63$ ) and survival of fry (48$100 \%$ ) were variable between sediments suggesting the sediment type and strain of fish may influence lingering effects after cessation of exposure.

The results of this research indicate SMB eggs are robust, but that newly hatched larvae, which are temporarily immobile, may be vulnerable to the effects of suspended sediment. These experiments may conservatively overestimate the magnitude of this effect because in nature, SMB males can prevent particles from burying these life stages (eggs and larvae). Survival of the mobile swim-up fry suggests this life stage is more tolerant of TSS concentrations up to $500 \mathrm{mg} / \mathrm{L}$. However, growth was reduced as turbidity increased, which is similar to results reported for SMB and other Centrarchids of similar to slightly larger sizes in other studies (Reid et al. 1999; Sweka and Hartman 2003).

\footnotetext{
${ }^{1}$ Suedel, B. C., J. L. Wilkens, and A. J. Kennedy. In prep. Effects of suspended sediment on smallmouth bass (Micropterus dolomieu) eggs and larvae. Submitted to Journal of Great Lakes Research.
} 


\section{Table 1. Survival and growth of smallmouth bass larvae and fry exposed to suspended sediment collected from Fairport Harbor and Grand Haven Harbor for 72 hours (mean \pm SD).}

\begin{tabular}{|c|c|c|c|c|c|}
\hline \multirow[b]{2}{*}{ Sediment } & \multicolumn{2}{|c|}{ Larvae } & \multicolumn{3}{|c|}{ Swim-up Fry } \\
\hline & $\begin{array}{l}\text { Measured } \\
\text { TSS (mg/L) }\end{array}$ & $\begin{array}{c}\text { Post hatch } \\
\text { survival (\%) }\end{array}$ & $\begin{array}{c}\text { Measured } \\
\text { TSS (mg/L) }\end{array}$ & $\begin{array}{c}\text { Survival } \\
(\%)\end{array}$ & $\begin{array}{l}\text { Change in } \\
\text { weight (\%) }\end{array}$ \\
\hline \multirow{4}{*}{ Fairport Harbor } & $0 \pm 3$ & $84 \pm 5$ & $0 \pm 4$ & $99 \pm 1$ & +43 \\
\hline & $100 \pm 13$ & $60 \pm 14^{*}$ & $91 \pm 11$ & $100 \pm 1$ & +48 \\
\hline & $247 \pm 24$ & $16 \pm 9^{*}$ & $221 \pm 17$ & $100 \pm 0$ & +38 \\
\hline & $547 \pm 47$ & $26 \pm 16^{*}$ & $452 \pm 39$ & $90 \pm 17$ & $+5^{*}$ \\
\hline \multirow{4}{*}{$\begin{array}{l}\text { Grand Haven } \\
\text { Harbor }\end{array}$} & $0 \pm 2$ & $81 \pm 5$ & $0 \pm 3$ & $100 \pm 0$ & +18 \\
\hline & $111 \pm 10$ & $9 \pm 5^{*}$ & $110 \pm 17$ & $100 \pm 0$ & +9 \\
\hline & $258 \pm 9$ & $15 \pm 10^{*}$ & $263 \pm 37$ & $100 \pm 0$ & $-9^{*}$ \\
\hline & $546 \pm 46$ & $6 \pm 6^{*}$ & $528 \pm 40$ & $95 \pm 6$ & $-23^{*}$ \\
\hline
\end{tabular}

Note: Asterisks $\left(^{*}\right)$ denote a significant difference $(P<0.05)$ relative to the control $(0 \mathrm{mg} / \mathrm{L} \mathrm{TSS})$. The mean initial dry weight at the start of the experiment for Fairport Harbor and Grand Haven Harbor fish was 0.0021 and 0.0022 , respectively $(\mathrm{N}=30$ fish) (Suedel et al. 2016 In prep) 1 .

EASTERN OYSTER IN THE JAMES RIVER: Environmental windows are imposed to protect oyster beds from potential impacts of sediment resuspension resulting from removal of dredged materials starting in late spring and extending into the fall; timeframes which coincide with oyster spawning activities in the James River, Virginia. As a result, dredging is restricted from late winter to early spring to remove sediments that have accumulated in tidal reaches immediately upstream of areas used for oyster culture and harvesting.

Field-collected oysters were exposed for 7 days at the same resuspended sediment concentrations as the previous receptors $(0,100,250,500 \mathrm{mg} / \mathrm{L})$. Half of the collected oysters were positioned horizontally at the bottom of the aquarium on a screen, the other half were mounted vertically in a monitoring apparatus where shell movements were electronically monitored (Figure 2) (Suedel et al. 2015). Endpoints measured were survival, percent of time the shell was open, total number of shell movements, weight change, and condition index.

No mortality occurred during the 7 day exposure period and no statistically significant differences $(F=0.43, P=0.7332)$ were seen among treatments with respect to percent of exposure time with shells open (Figure 3). Numbers of shell movements among treatments also did not differ significantly $(F=1.50, P=0.2234)$. No significant differences $(F=0.84, P=0.4750)$ in weight change among treatments were noted for the combined group of vertical and horizontal oysters; however, weight change in oysters attached vertically to an apparatus was significantly less $(F=37.29, P<0.0001)$ than in oysters lying horizontally on the bottoms of the aquaria in every treatment. This may be attributable to the apparatus blocking some suspended sediment and the corresponding nutrients from reaching the oysters attached to the apparatus. No significant differences $(F=1.18, P=0.3271)$ were observed among treatments for condition index (for either shell orientation), suggesting that exposure up to 7 days duration at concentrations as high as 500 $\mathrm{mg} / \mathrm{L}$ had no effect on growth.

\footnotetext{
${ }^{1}$ Suedel, B. C., J. L. Wilkens, and A. J. Kennedy. In prep. Effects of suspended sediment on smallmouth bass (Micropterus dolomieu) eggs and larvae. Submitted to Journal of Great Lakes Research.
} 


\section{ERDC TN-DOER-E42}

\section{March 2017}

This finding is conservative in that suspended sediment concentrations were continuous and sustained for a 7 day exposure period, as opposed both to natural tidal settings where exposure concentrations vary in response to continuously changing local currents and to maintenance dredging scenarios, where exposure is transient. Results of this study were consistent with those of previous investigations (e.g., Mackin 1962; Carriker 1986) that demonstrated that eastern oysters show relatively high tolerance levels to this physical stressor.

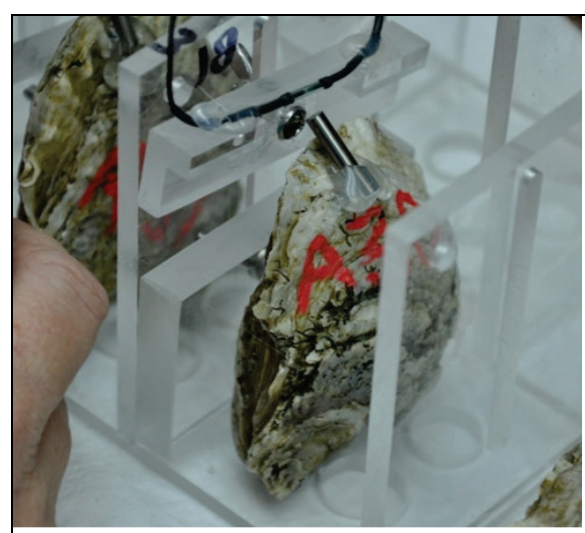

Monitoring Apparatus

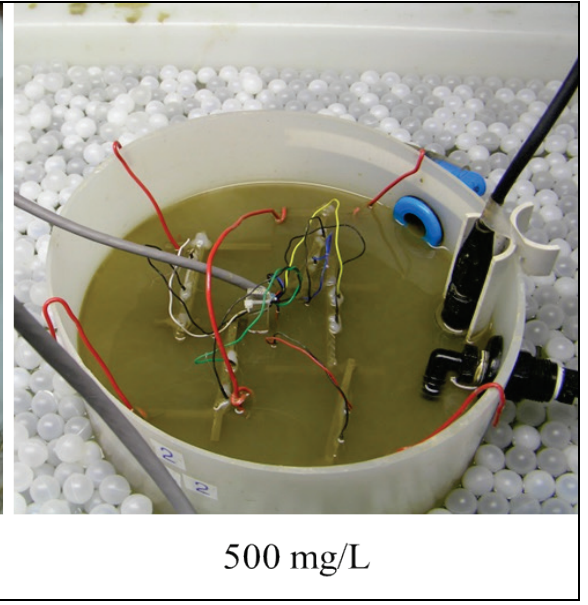

Figure 2. Eastern oysters mounted in monitoring apparatus (Suedel et al. 2015).

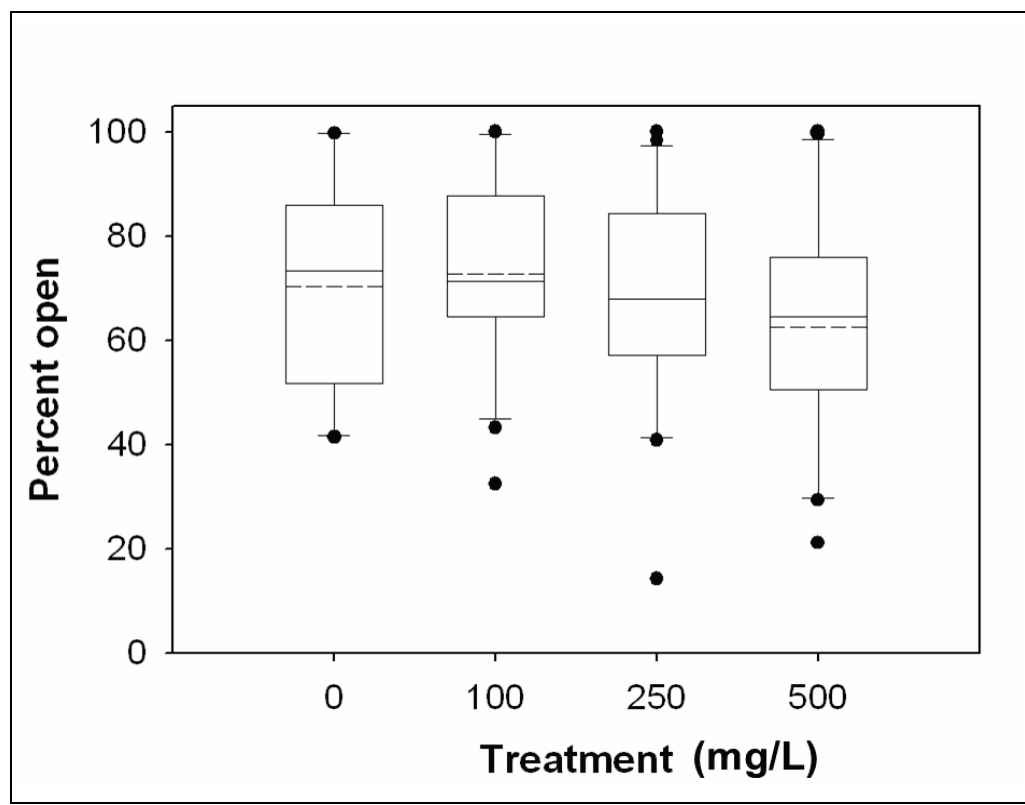

Figure 3. Box and whisker plots for percent of total experimental duration that oyster shells were open during exposure to suspended sediment. Boxes include $25^{\text {th }}$ and $75^{\text {th }}$ percentiles; whiskers extend to $10^{\text {th }}$ and $90^{\text {th }}$ percentiles; dots show outliers. Medians and means are indicated by horizontal solid and dashed lines, respectively, within the boxes (Suedel et al. 2015). 
ATLANTIC STURGEON IN SAVANNAH HARBOR: Juvenile Atlantic sturgeon obtained from a hatchery were tested in FLEES using sediment collected from Savannah Harbor, South Carolina, to determine the effects on short-term survival and swimming performance (Wilkens et al. 2015). Of the 90 fish exposed, 86 (96\%) survived the experiment (Table 2); of the four fish that died, one was exposed to $250 \mathrm{mg} / \mathrm{L}$ and three to $500 \mathrm{mg} / \mathrm{L}$. Swimming performance results indicated that nearly all fish were positively rheotactic. Critical swim speeds (Ucrits) were moderate $(21.0-31.3 \mathrm{~cm} / \mathrm{s})$, whether measured as absolute values or as relative values, with no statistically significant differences $(\mathrm{P}>0.05)$ among treatments. Behavior was dominated by contact-based locomotion and station-holding (ability to maintain station in flowing water).

\begin{tabular}{|c|c|c|c|c|}
\hline \multirow[b]{2}{*}{ Endpoint } & \multicolumn{4}{|c|}{ Suspended Sediment Concentrations (mg/L)* } \\
\hline & 0 & 100 & 250 & 500 \\
\hline Survival (\%) & 100 & 100 & 96 & 88 \\
\hline Rheotaxis (\%) & 100 & 100 & 100 & 96 \\
\hline Ucrit $(\mathrm{cm} / \mathrm{s})$ & $21.0 \pm 12.6$ & $23.3 \pm 9.4$ & $31.3 \pm 14.7$ & $29.6 \pm 19.2$ \\
\hline Ucrit (BLS) & $1.45 \pm 0.72$ & $1.89 \pm 0.88$ & $2.15 \pm 0.91$ & $2.09 \pm 1.29$ \\
\hline Contact-based station-holding (\%) & $81.7 \pm 40.1$ & $51.0 \pm 51.9$ & $75.7 \pm 44.9$ & $69.3 \pm 47.5$ \\
\hline
\end{tabular}

Note: * $\mathrm{N}=24$ fish per treatment and 18 fish in controls for survival; $\mathrm{N}=8$ fish per treatment and 6 fish in controls for swim performance. Values are means \pm SD of combined experiments. Ucrit (BLS) = body lengths per second (Wilkens et al. 2015).

The absence of substantial or significant short term effects on survival and swimming performance suggest that impacts of sediment plumes caused by dredging activities or natural processes in nature, where fish have freedom of movement and the power to rapidly escape, are minimal. At these experimental concentrations individual fitness of juvenile sturgeon and capacity to persist in the presence of resuspended sediments may be more important (Wilkens et al. 2015).

SUMMARY: Naturally shoaled sediments collected from navigation channels where sieved to yield fine-grained sediment particles which are most likely to remain in suspension and migrate away from an active dredge. FLEES studies used this sediment to determine the impact of resuspended sediment on several aquatic species and life stages. The biological response data for the species evaluated suggest that sub-lethal and lethal effects at concentrations at and below 500 $\mathrm{mg} / \mathrm{L}$ over extended periods of exposure are unlikely to occur for all but the most sensitive life stage tested (e.g., temporarily immobile smallmouth bass larvae). These data may serve as a guide for other dredging projects where these species occur (Gordon et al. 2015).

These FLEES studies represent worst case exposure scenarios because: 1) in the field, motile organisms or life stages will have the ability to avoid the sediment plume, thereby reducing their exposure; 2) most dredging operations are not stationary and continuously move as dredge materials are removed; and 3) the fanning behavior of fish, such as SMB, can disperse fine-grained sediments from their nest, ameliorating the effects resuspended sediment have on eggs and larvae. Longer-term exposures (e.g., greater than 3 days) involving suspended sediment concentrations above $500 \mathrm{mg} / \mathrm{L}$, would be very unlikely to occur under either ambient or dredging-induced conditions except within very short distances from the source (Wilber and Clarke 2001). 
CONCLUSION: The results suggest that detailed, site-specific knowledge of the dredge project, sediment type, organism life history and exposure can better support decisions regarding the development of adequately protective EW risk management practices.

POINTS OF CONTACT: For additional information, contact Justin Wilkens (601-634-2421, Justin.L.Wilkens@usace.army.mil) or Dr. Burton Suedel (601-634-4578, Burton.Suedel@usace. army.mil ). This technical note should be cited as follows:

Wilkens, J. L., and B. C. Suedel. 2017. Using the fish larvae and egg exposure system to generate effects data for informing environmental windows. DOER Technical Notes Collection. ERDC TN-DOER-E42. Vicksburg, MS: U.S. Army Engineer Research and Development Center. http://el.erdc.usace.army.mil/.

\section{REFERENCES}

Carriker, M. R. 1986. Influence of suspended particles on biology of oyster larvae in estuaries. American Malacology Bulletin 3:41-49.

Cooke, S. J., D. P. Philipp, D. H. Wahl, and P. J. Weatherhead. 2006. Energetics of parental care in six syntopic centrarchid fishes. Oecologia 148:235-249.

Gordon, A. K., and C. G. Palmer. 2015. Defining an exposure-response relationship for suspended kaolin clay particulates and aquatic organisms: Work toward defining a water quality guideline for suspended solids. Environmental Toxicology and Chemistry 34:907-912.

Lutz, C. H., D. G. Clarke, and B. C. Suedel. 2012. A fish larvae and egg exposure system (FLEES) for evaluating the effects of suspended sediments on aquatic life. DOER Technical Notes Collection. ERDC TN-DOER-E32. Vicksburg, MS: U.S. Army Engineer Research and Development Center. http://el.erdc.usace.army.mill.

Mackin, J. G. 1962. Canal dredging and siltation in Louisiana bays. Publication of the Institute of Marine Sciences University of Texas 7:262-314.

Reid, S. M., M. G. Fox, and T. H. Whillans. 1999. Influence of turbidity on piscivory in largemouth bass (Micropterus salmoides). Canadian Journal of Fisheries and Aquatic Sciences 56: 1369-1369.

Reine, K. J., D. D. Dickerson, and D. G. Clarke. 1998. Environmental windows associated with dredging operations. DOER Technical Notes Collection. ERDC TN DOER-E2. Vicksburg, MS: U.S. Army Engineer Research and Development Center. http://el.erdc.usace.army.mil/.

Reine, K. J., D. G. Clarke, D. D. Dickerson, and S. Pickard. 2007. Assessment of potential impacts of bucket dredging plumes on walleye spawning habitat in Maumee Bay, Ohio. In Proceedings of the 18th World Dredging Congress (WODCON XVIII), Lake Buena Vista, FL.

Roseman, E. F., W. W. Taylor, D. B. Hayes, R. C. Haas, R. L. Knight, and K. O. Paxton. 1996. Walleye egg deposition and survival on reefs in western Lake Erie (USA). Annales Zoologici Fennici 33:341-351.

Suedel, B. C., J. Kim, D. G. Clarke and I. Linkov. 2008. A risk-informed decision framework for setting environmental windows for dredging projects. Science of the Total Environment 403:1-11.

Suedel, B. C., C. H. Lutz, J. U. Clarke, and D. G. Clarke. 2012. The effects of suspended sediment on walleye (Sander vitreus) eggs. Journal of Soils and Sediments 12:995-1003.

Suedel, B. C., J. U. Clarke, C. H. Lutz, D. G. Clarke, C. Godard-Codding, and J. Maul. 2014. Suspended sediment effects on walleye (Sander vitreus). Journal of Great Lakes Research 40:141-148. 


\section{ERDC TN-DOER-E42 \\ March 2017}

Suedel, B. C., J. U. Clarke, J. Wilkens, C. H. Lutz, and D. G. Clarke. 2015. The effects of simulated suspended sediment plume on eastern oyster (Crassostrea virginica) survival, growth, and condition. Estuaries and Coasts 38:578-589.

Sweka, J. A., K. J. Hartman. 2003. Reduction of reactive distance and foraging success in smallmouth bass, Micropterus dolomieu, exposed to elevated turbidity levels. Environmental Biology of Fishes 67:341-347.

Wilber, D. H., and D. G. Clarke. 2001. Biological effects of suspended sediments: a review of suspended sediment impacts on fish and shellfish with relation to dredging activities in estuaries. North American Journal of Fisheries Management 21:855-875.

Wilkens, J. L., A. W. Katzenmeyer, N. M. Hahn, J. J. Hoover, and B. C. Suedel. 2015. Laboratory test of suspended sediment effects on short-term survival and swimming performance of juvenile Atlantic sturgeon (Acipenser oxyrinchus oxyrinchus). Journal of Applied Ichthyology 1-7.

NOTE: The contents of this technical note are not to be used for advertising, publication, or promotional purposes. Citation of trade names does not constitute an official endorsement or approval of the use of such products. 